\title{
Finansal Açıdan Başarısız Firmaların Lojistik Regresyon Analizi ile Tahmin Edilmesi: BİST 100'de Bir Uygulama
}

DOI: 10.26466/opus.950625

\author{
* \\ Merve Arslan ${ }^{*}$ - İsmail Erkan Çelik** \\ * Dr., Haliç Üniversitesi, İstanbul/Türkiye \\ E-Posta: mervearslan@halic.edu.tr \\ ORCID: $\underline{0000-0001-5252-3741}$ \\ ** Dr.Öğr.Üyesi, Doğuş Üniversitesi, İstanbul/Türkiye \\ E-Posta: ismailerkancelik@gmail.com \\ ORCID: $\quad \underline{0000-0002-2274-0750}$
}

Öz

Dünyada gün geçtikçe artan rekabet koşullarında işletmelerin hedeflerine ulaşabilmeleri ancak finansal açıdan güçlü olup olmadıkları ile mümkündür. Firmalar, finansal başarısızlı̆̆a neden olan riskleri ya önceden öngörüp minimize etmeli ya da mümkünse tamamen ortadan kaldırmalıdır. Finansal başarısızlıklarının önceden tahmin edilmesi; işletmelerin gelecekte doğabilecek finansal riskleri önceden tespit ederek, önlemleri şimdiden alması açısından çok önemli bir husustur. Bu çalışmanın temel amacı, çalışmada Borsa İstanbul 100 Endeksinde (BIST 100) işlem göre firmaların; finansal başarısızlık göstergesi olabilecek, finansal olarak başarll ve başarısız firmaların belirlenmesinde ve kategorize edilmesinde istatistiksel olarak hangi oranları anlaml olup olamayacağını ortaya koymak ve bu belirlenen oranlar yardımı ile başarısızlı̆̆ı öngörebilmek amacıyla çeşitli lojistik regresyon modellerinin geliştirilmesidir. Bu amaçla çalışmada BIST 100 yer alan 26 firmanın 2019 yılına ait finansal oran verileri kullanılmıştır. İlgili çalışmada Lojistik Regresyon analizi gerçekleştirilerek elde edilen bulgulara göre finansal açıdan başarılı ve başarısız firmaların ayrıştırılmasında "faiz karşılama oranı" ile "faaliyet kar marjı" rasyolarının ayırt edici rasyolar olabileceği sonucuna erişilmiş̧tir.

Anahtar Kelimeler: Finansal Başarı ve Başarısızlık, Rasyo Analiz, Lojistik Regresyon Analizi. 


\title{
Estimating Financially Failed Firms Using Logistic Regression Analysis: An Application in BIST 100
}

*

\begin{abstract}
In today's world order, businesses can achieve their goals only if they are financially strong. Firms should be able to anticipate the risks of financial failure as early as possible, minimize this risk and eliminate it completely if possible. Anticipating financial failures in advance is very important in terms of detecting and preventing financial risks that businesses may face in the future. With this study, the companies operating in the BIST 100 Index; It is the determination of statistically significant ratios in identifying and categorizing financially successful and unsuccessful firms that can be an indicator of their financial failure. With the help of these determined ratios, various logistic regression models are developed in order to predict failure. For this purpose, the financial rate data of 26 companies included in the 2019 BIST 100 were used in the study. According to the findings obtained by performing Logistic Regression analysis in the related study, it has been concluded that "interest coverage ratio" and "operating profit margin" ratios may be determinants in distinguishing financially successful and unsuccessful companies.
\end{abstract}

Key Words: Financial Success and Failure, Ratio Analysis, Logistic Regression Analysis. 


\section{Giriş}

Finansal başarısızlık, firmanın yükümlülüklerini yerine getirmekte zorlanması ya da yerine getirememe durumu olarak tanımlanabilir. Aslında finansal başarısızlık durumu, firmaların ödeme gücünün azalması ya da tamamıla ortadan kalkmasıdır. Herhangi bir firma için "finansal açıdan başarısız" denilebilmesi çeşitli kriterlerin sağlanmasını gerekli kılmaktadır. Konu ile ilgili olarak literatür incelendiğinde finansal başarısızlığın belirlenmesinde; firmaların vadesi gelmiş yükümlülüklerini ödeyememesi, karşılıksız çek yazması, tahvil faizini ödeyememesi, üç yıl üst üste zarar etmiş olmaları, aktif tutarının \%10'unu kaybetmeleri, öz sermayelerinin azalması, üretim çarkının durdurulması ya da iflas etmesi gibi çok çeşitli olan farklı bir çok kriterlerle karşılaşılmıştır (Beaver, 1966, s.72-73).

İşletmeler kar amacı önceliğine sahip, yaşamlarının ise teknik düzeyde sonsuza dek sürmesi düşünülerek kurulmaktadırlar. Ancak işletmeler bu süreç içinde farklı problemlerle karşılaşabilmektedir. Bu sorunların tespit edilememesi ve çözülememesi işletmelerin başarısızlıklarına neden olmaktadır. Başarısızlık işletmelerin karşılaşmak istemeyecekleri bir durumdur. İşletmelerin bazıları kurulma aşamasında 1,2 yıl sonra yaşam süreçlerinin başında başarısızlığa uğrayabiliyor iken diğer bazı işletmeler gelişip büyüme süreçlerini başaralı şekilde sürdürebilmektedir. (Gitman, 1992, s.616). İşletmelerin kuruluş amaçlarını gerçekleştiremedikleri yada ulaşmayı hedefledikleri amaçlara ulaşamayıp faaliyetlerine son vermek zorunda kaldıkları durumlar başarısızlık olarak nitelendirilmektedir (Büker vd., 2007, s.567). İşletmeler için "başarısızlık" şeklinde ifade edilen bu tür sorunların iki temel başlıkta ifade edilmesi mümkündür. Bunlar:

- Ekonomik başarısızlıklar

- Finansal başarısızlıklar

Genel bir ifadeyle finansal başarısızlık kavramının; finansal yapıda bozulmaların yaşanması, sıkıntı içine girme, borçların ödenememesi, sıkıntılı sürecin devam etmesiyle başarısızlığın doğması ve neticede iflasın gerçekleşmesi olarak tanımlanması mümkündür. İflas, finansal sorunların yaşanması ile başlayarak mahkemede neticelenen bir süreçtir ve finansal başarısızlığın özel bir halidir (Aktaş, 1997, s.5). 
Bir firmanın finansal başarısızlık süreci, yükümlülüklerini yerine getirememesi süreci ile başlamakta ve iflasa kadar uzanmaktadır. Finansal başarısızlık durumu firmaların karşıya kalabilecekleri en önemli problemlerdendir. Bilhassa kırılgan ekonomik yapıya sahip ülkemiz açısından konu ele alındığında, firmalarda finansal başarısızlığa sebebiyet veren finansal oranların tahmin edebilmesi ve başarısızlığın önlenmesi için gereken önlemlerin alınması gereklilik arz etmektedir. Finansal başarısızlık firma içi/firma dışı olarak çeşitli nedenlerden doğabilmektedir ancak yöneticilerin firma dişı kaynaklı faktörlere müdahale edemeyecekleri açıktır. Buna karşın firma bünyesinde kaynaklanan başarısızlık sebeplerini öncesinden öngörüp müdahalelerde bulunulabilir. Bu nedenle son zamanlarda yapılan çalışmalarda, finansal başarısızlıklara hangi oranların neden olduğu ve finansal başarısızlığın belirlenmesinde hangi oranların belirleyici olduğu konusu üzerinde önemle durulmaktadır. Finansal başarısızlığın saptanmasında; yapay sinir ağları, lojistik regresyon analizi, diskriminant analizi gibi tahmin yöntemlerinin kullanımı ile karşılaşılmıştır.

$\mathrm{Bu}$ çalışma ile hedeflenen hisseleri BİST100'de işlem görmekte olan firmaların finansal başarısızlıklarının ölçümlenmesinde anlamlı, güvenilir bir modelin oluşturulmasıdır. Bu hedefle, önce "finansal başarısızlık" araştırılmış ve hangi firmaların finansal anlamda başarılı ve başarısız olabilecekleri ayrımı yapılmaya çalışılmıştır. Daha sonra finansal oranlar hesaplanarak bu finansal rasyolar ile lojistik regresyon analizi yapılmış olup, finansal başarı-başarısızlığın belirlenmesi, hangi finansal oranların finansal başarı ve başarısızlığı tespit edebileceği üzerine bir araştırma yapılması hedeflenmiştir.

\section{Literatür İncelemesi}

Tek değişkenli modelin kullanılması ile finansal başarısızlığın tahmin edilmesine ilişkin Beaver $(1966,1968)$, Tamari (1966) tarafından ele alınan çalışmalar daha sonraki çalışmalara yol gösterici olduklarından literatürde önemli bir yeri vardır. Tek değişkenli modeller ile finansal başarısızlık tahminlenmesinde, finansal oranlar tek tek ele alındığından, incelenen orana göre birbiri ile çelişen sonuçlara ulaşılabilir. Bundan kaçınmak isteyen araştırmacılar, birden çok finansal oranı ve oranlar 
arasındaki ilişkiyi tespit edebilmeye imkân tanıyan çok değişkenli modelleri kullanmayı tercih etmişlerdir.

Altman (1968) tarafından çoklu diskriminant analizi, Żmijewski (1984) tarafından lojit ve probit modeller, Ohlson (1980) tarafından lojistik regresyon analizi kullanılmıştır.

Beaver (1966) tarafından 1954-1964 arasında 79 başarısız işletme ile yine aynı sektörde işlem gören 79 başarılı işletme ele alınmıştır. 30 finansal oran 6 grup altında bir araya getirilmiş ve her bir gruptan sadece bir oran alıp değerlendirilmiştir. Sonuçlara göre, kimi oranların en az 5 yıl öncesine kadar başarısızlığın tahmin edilmesinde kullanılabileceği tespit edilmiştir.

Tamari (1966) ise tek bir değişken kullanmak yerine birden fazla değişkeni kullanarak, 1956-1960 için, yeni iflas eden 12 işletmeyle, iflasını isteyen 16 endüstri firmasının verilerini kullanmıştır. Finansal oranlar ile risk indeksi oluşturulmuştur. İşletmelerin finansal başarılarını 0 ile 100 arasında puanlandırmıştır. Çalışma sonucunda risk indeks modeli çerçevesinde, 30' dan eksik puanı olan işletmelerin \%50'sinin, 30 puandan yüksek puan alan işletmelerinse \%3'ünün iflas ettiği görülmüştür.

Altman (1968) tarafından çoklu diskrimant analizi kullanılmış olup; 1946- 1965 aralığında iflas etmiş olan ve aktif büyüklüğü 0,7-25,9 milyon dolar olan üretim firmalarını ve aynı endüstride faaliyet sürdüren aktif büyüklüğü 1-25 milyon dolar olan işletmeleri iki grup olarak eşleştirip incelemiştir. Sonuç olarak; firma iflaslarının, \%95 oranında bir yıl öncesinde, \%72 oranında iki yıl öncesinde tahmin edilebilmektedir.

Ohlson (1980) tarafından 1970 -1976 için 105 iflas etmiş ile 2058 iflas etmemiş firmaların verileri ile lojistik regresyon tekniği kullanılarak; firma iflaslarının tahmin edilmesi hedeflenmiştir. Elde edilen bulgular, iflas edilmeden bir yıl öncesi için, iflas edilmeden iki yıl öncesi için son olarak bir ve iki yıl öncesi birleştirerek kurulan farklı modellerde sırayla; $\% 96,12$ / \%95,55 / \%92,84 oranında başarılı tahminlere erişilmiştir.

Siedlecki (2014) tarafından, Polonya'da büyük, tanınmış başarılı bir firma ile iflas eden bir firmanın 2001-2010 aralığındaki finansal verileri kullanılarak; finansal başarısızlığın tahmin edilmesi üzerine çalışılmıştır. Finansal başarısızlığın tahminlenmesinde, finansal verilerin kullanılıp kullanılmayacağı lojistik regresyon ile araştırılmıştır. Çalışmada seçili 
finansal parametreler ile finansal başarının değerlendirilmesinin mümkün olduğu tespit edilmiştir.

\section{Yöntem}

$\mathrm{Bu}$ çalışma ile amaçlanan; işletmelerin karşılaşabileceği finansal başarısızlık durumunun lojistik regresyon ile tahmin edilebilirliğinin araştırılmasıdır. Bunun için $\mathrm{KAP}^{\prime} \mathrm{da}$ elde edilen firma finansal verilerinden hesaplanan finansal oranlar girdi olarak kullanılacaktır (Kap, 2021). Çalışmada 2019 yılı için BİST100 Endeksinde yer alan 26 firmanın finansal raporlarındaki veriler dikkate alınarak 17 adet finansal rasyo oranları hesaplanmıştır. Ancak daha sonra modelin istatistiksel olarak anlamlı olabilmesi için 11 adet finansal rasyo oranları analiz edilmiştir. Analizimizde muhtemel bağımsız değişkenlerimiz olan rasyolar aşağıdaki tabloda yer almaktadır.

\section{Tablo 1. Analize Dahil Edilen Bağımsız Değişkenler}

\begin{tabular}{|c|c|c|}
\hline Oran Grubu & Oran Adı & Hesap Edilişi \\
\hline \multirow[t]{2}{*}{ Likidite Oranı } & Cari oran & $\begin{array}{l}\text { Dönen varlıklar / Kısa vadeli yabancı } \\
\text { kaynakla }\end{array}$ \\
\hline & Toplam Borç/Özkaynaklar & Toplam Borç/Özkaynaklar \\
\hline \multirow[t]{6}{*}{ Mali Yapı Oranları } & Duran varlıklar/Özkaynaklar & Duran varlıklar/Özkaynaklar \\
\hline & Faiz karşılama oranı & FVÖK / Faiz giderleri \\
\hline & Öz kaynak Devir Hızı & Net satışlar / Özkaynaklar \\
\hline & Aktif Devir Hızı & Net satışlar / Aktif toplamı \\
\hline & Alacak Devir Hızı & Net satışlar / Ticari alacaklar \\
\hline & Dönen Varlık Devir Hızı & Net satışlar / Dönen varlıklar \\
\hline \multirow{6}{*}{$\begin{array}{l}\text { Faaliyet Devir Hızı } \\
\text { Oranları }\end{array}$} & Maddi Duran Varlık Devir Hızı & Net satışlar / Maddi duran varlıklar \\
\hline & Ortalama Etkinlik Süresi & $\begin{array}{l}\text { Ortalama tahsilat süresi }+ \text { Ortalama } \\
\text { stokta kalma süresi }\end{array}$ \\
\hline & Ortalama Stokta Kalma Süresi & 360 / Stok devir hizı \\
\hline & Ortalama Tahsilat Süresi & 360 / Alacak devir hızı \\
\hline & Stok Devir Hizı & Satışların maliyeti / Ortalama stok tutarı \\
\hline & Ticari Borç Devir Hızı & Satışların maliyeti / Ticari borçlar \\
\hline \multirow[t]{2}{*}{ Kârlılık Oranları } & Net Kar Marj1 & Net kâr / Net satışlar \\
\hline & Faaliyet Kar Marjı & Faaliyet kârı / Net satışlar \\
\hline
\end{tabular}

Çalışmada 2019 yılının sonunda kar/zarar durumlarına bağlı olarak firmalar başarılı ve başarısız olarak ikiye ayrılmıştır. Başarılı firmalar 2019 yılının sonunda kar eden firmalar başarılı kabul edilirken; 2019 yılının sonunda zarar eden firmalar başarısız olarak değerlendirilmiş olup, 
Lojistik regresyon kategorik bağımlı değişkeni aşağıdaki gibi sembolize edilmiştir;

Tablo 2. Analize Dahil Edilen Bağımsız Değişkenler

\begin{tabular}{lll}
\hline & \multicolumn{2}{c}{ Başarılı-Başarısız Firmaların Kategorize Edilmesi } \\
\hline $\mathrm{y}$ & 1 & Başarılı Firmalar \\
& 0 & Başarısız Firmalar \\
\hline
\end{tabular}

Çalışmada firma başarısızlıklarını tahmin edilmesi için lojistik regresyon analizi uygulanmıştır. Logit analiz olarak da bilinen lojistik regresyon analiz yöntemi, çok değişkenli istatistiksel analiz yöntemidir (Doğrul, 2009, s. 70-72). Bu metodun kullanımı ile amaçlanan; bağımlı değişkenin iki değeri arasında geçişliliğine neden olan bağımsız değişken değerlerini olasılıklarla tespit edilmesidir. Lojistik regresyon yöntemi, olasılık ve olasılıklar oranı "odds" kavramlarına dayanmaktadır. Lojistik regresyonda olasılıklar oranı, herhangi bir olayın gerçekleşme olasılığının gerçekleşememe olasılığına oranı şeklinde tanımlanmaktadır. (Mertler ve Vannatta, 2005, s.134).

\section{Bulgular}

Tablo 3. Lojistik Regresyon 1. Model Çıktısı

\begin{tabular}{|c|c|c|c|c|}
\hline Variable & Coefficient & Std. Error & z-Statistic & Prob. \\
\hline Özkaynak Devir Hızı & 0.006490 & 0.073009 & 0.088900 & 0.9292 \\
\hline Aktif Devir Hızı & 2.453401 & 0.960847 & 2.553373 & 0.0107 \\
\hline Cari Oran & 1.688156 & 0.550839 & 3.064698 & 0.0022 \\
\hline Sabit & -4.652492 & 1.223442 & -3.802789 & 0.0001 \\
\hline McFadden R-squared & 0.518198 & \multicolumn{2}{|c|}{ Mean dependent var } & 0.500000 \\
\hline S.D. dependent var & 0.509902 & \multicolumn{2}{|c|}{ S.E. of regression } & 0.369393 \\
\hline Akaike info criterion & 0.975612 & \multicolumn{2}{|c|}{ Sum squared resid } & 3.001924 \\
\hline Schwarz criterion & 1.169165 & \multicolumn{2}{|c|}{ Log likelihood } & -8.682951 \\
\hline Hannan-Quinn criter. & 1.031348 & \multicolumn{2}{|c|}{ Deviance } & 17.36590 \\
\hline Restr. deviance & 36.04365 & \multicolumn{2}{|c|}{ Restr. log likelihood- } & -18.02183 \\
\hline LR statistic & 18.67775 & \multicolumn{2}{|c|}{ Avg. log likelihood } & -0.333960 \\
\hline Prob(LR statistic) & 0.000319 & \multirow{3}{*}{\multicolumn{2}{|c|}{ Total obs }} & \\
\hline Obs with Dep $=0$ & 13 & & & 26 \\
\hline Obs with Dep $=1$ & 13 & & & \\
\hline
\end{tabular}

Yukarıdaki Tabloda Lojistik Regresyon 1. Model Test sonucu mevcuttur. Model istatistiksel olarak anlamlıdır (Prob LR Statistic: 0.000319) dolayısıyla çıktılar yorumlanabilir. 
Lojistik Regresyon 1. Model Test sonucuna göre "Aktif Devir Hızı" ve "Cari Oran" değişkenlerinin katsayılarının, finansal olarak başarılı ya da başarısız firmaları belirlemede, istatistiksel olarak anlamlı olduğu görülmektedir. Dolayısıyla özkaynak devir hızı, aktif devir hızı ve cari oran değişkenlerinin modele dahil edilmesi ile ulaşılan analiz sonucuna göre; Aktif Devir Hızı ve Cari Oran rasyolarının, firma başarımlarını belirleme noktasında ayırt edici rasyolar olduğunu bu çalışmada tespit edilmiştir. Özkaynak devir hızı ise finansal olarak başarılı ya da başarısız firmaları ayırt etmede, istatistiksel olarak anlamlı bir rasyo olmadığ 1 sonucuna ulaşılmıştır.

Tablo 4. Lojistik Regresyon 1. Model Çıktılarının Yorumlanması

\begin{tabular}{|c|c|c|}
\hline Bağımsız Değişkenler & Anlamlılık & Karar \\
\hline Özkaynak Devir Hızı & $\begin{array}{l}\text { Lojistik Regresyon } 0.9292>0,05 \\
\text { Analizi }\end{array}$ & $\begin{array}{l}\text { Özkaynak Devir Hızı } \\
\text { Başarılı/Başarısız firmaların } \\
\text { belirlenmesinde anlamlı bir } \\
\text { farklılık göstermemektedir. }\end{array}$ \\
\hline Aktif Devir Hızı & $\begin{array}{l}\text { Lojistik Regresyon } 0.0107<0,05 \\
\text { Analizi }\end{array}$ & $\begin{array}{l}\text { Aktif Devir Hızı Başarılı/Başarısız } \\
\text { firmaların belirlenmesinde } \\
\text { anlamlı bir farklılık } \\
\text { göstermektedir. }\end{array}$ \\
\hline Cari Oran & $\begin{array}{l}\text { Lojistik Regresyon } 0.0022<0,05 \\
\text { Analizi }\end{array}$ & $\begin{array}{l}\text { Cari Oran Başarılı/Başarısız } \\
\text { firmaların belirlenmesinde } \\
\text { anlamlı bir farklılık } \\
\text { göstermektedir. }\end{array}$ \\
\hline
\end{tabular}

Tablo 5. Lojistik Regresyon 1. Modelinin Uygunluk Testi

\begin{tabular}{|c|c|c|c|c|c|c|c|c|}
\hline & \multicolumn{3}{|c|}{ Quantile of Risk } & \multicolumn{2}{|l|}{ Dep $=0$} & \multirow{2}{*}{$\begin{array}{l}\text { Dep=1 } \\
\text { Expect }\end{array}$} & \multirow{2}{*}{$\begin{array}{l}\text { Total } \\
\text { Obs }\end{array}$} & \multirow{2}{*}{$\begin{array}{l}\text { H-L } \\
\text { Value } \\
\end{array}$} \\
\hline & Low & High & Actual & Expect & Actual & & & \\
\hline 1 & 0.0228 & 0.0252 & 2 & 1.95203 & 0 & 0.04797 & 2 & 0.04915 \\
\hline 2 & 0.0301 & 0.0618 & 3 & 2.86547 & 0 & 0.13453 & 3 & 0.14085 \\
\hline 3 & 0.0990 & 0.1032 & 2 & 1.79777 & 0 & 0.20223 & 2 & 0.22498 \\
\hline 4 & 0.1993 & 0.2031 & 2 & 2.39577 & 1 & 0.60423 & 3 & 0.32460 \\
\hline 5 & 0.3143 & 0.3551 & 1 & 1.97831 & 2 & 1.02169 & 3 & 1.42055 \\
\hline 6 & 0.4472 & 0.5296 & 2 & 1.02320 & 0 & 0.97680 & 2 & 1.90930 \\
\hline 7 & 0.5707 & 0.9024 & 1 & 0.78034 & 2 & 2.21966 & 3 & 0.08357 \\
\hline 8 & 0.9443 & 0.9498 & 0 & 0.10588 & 2 & 1.89412 & 2 & 0.11180 \\
\hline 9 & 0.9623 & 0.9787 & 0 & 0.08403 & 3 & 2.91597 & 3 & 0.08645 \\
\hline \multirow[t]{2}{*}{10} & 0.9828 & 1.0000 & 0 & 0.01721 & 3 & 2.98279 & 3 & 0.01731 \\
\hline & & Total & 13 & 13.0000 & 13 & 13.0000 & 26 & 4.36855 \\
\hline \multicolumn{3}{|c|}{$\overline{H-L}$ Statistic } & \multicolumn{2}{|l|}{4.3686} & \multicolumn{2}{|c|}{ Prob. Chi-Sq(8) } & \multicolumn{2}{|l|}{0.8224} \\
\hline \multicolumn{3}{|c|}{ Andrews Statistic } & \multicolumn{2}{|l|}{16.6960} & \multicolumn{2}{|c|}{ Prob. Chi-Sq(10) } & 0.0814 & \\
\hline
\end{tabular}


Yukarıda yer alan Tablo-5' de Hosmer ve Lemeshow test sonuçları yer almaktadır. Hosmer ve Lemeshow test istatistiği lojistik regresyon modelinin genel olarak test edilmesi amaciyla kullanılmaktadır. Test aşamasında kurulmuş olan lojistik modelin bu verilere uygunluğu belirlenmektedir. Bu amaçla sıfır ve karşıt hipotez şöyledir H0: Kurulmuş olan lojistik regresyon modeli uygundur.

H1: Kurulmuş olan lojistik regresyon modeli uygun değildir.

Şeklinde formüle edilmektedir. Modelin ki-kare değeri olan 4.3686 değeri ile bu değerin anlamlılık düzeyi 0.8224'a bakılmalıdır. Anlamlılık düzeyi $\mathrm{P}>0,05$ olduğundan; "kurulmuş olan lojistik regresyon modeli uygundur" şeklinde formüle edilmiş sıfır hipotezi kabul edilir. Böylece, lojistik regresyon modelinin uygun olduğu kararına erişilir.

Tablo-5'de Lojistik Regresyon 1. Modelinin Uygunluk test sonucu tablosunda, Hosmer Lemeshow Prob. Chi-Sq(8) değeri (0, 8224); 00,01/0,05/0,10 değerlerinden büyük olduğundan dolayı modelin uygun olduğuna karar verilir.

Tablo 6. Lojistik Regresyon 1. Modelin Beklenen Tahmin Tablosu

\begin{tabular}{|c|c|c|c|c|c|c|}
\hline & \multicolumn{3}{|c|}{ Estimated Equation } & \multicolumn{3}{|c|}{ Constant Probability } \\
\hline & Dep $=0$ & Dep $=1$ & Total & Dep $=0$ & Dep $=1$ & Total \\
\hline $\mathrm{P}(\mathrm{Dep}=1)<=\mathrm{C}$ & 11 & 3 & 14 & 13 & 13 & 26 \\
\hline$P($ Dep $=1)>C$ & 2 & 10 & 12 & 0 & 0 & 0 \\
\hline Total & 13 & 13 & 26 & 13 & 13 & 26 \\
\hline Correct & 11 & 10 & 21 & 13 & 0 & 13 \\
\hline$\%$ Correct & 84.62 & 76.92 & 80.77 & 100.00 & 0.00 & 50.00 \\
\hline$\%$ Incorrect & 15.38 & 23.08 & 19.23 & 0.00 & 100.00 & 50.00 \\
\hline Total Gain* & -15.38 & 76.92 & 30.77 & & & \\
\hline \multirow[t]{3}{*}{ Percent Gain ${ }^{* *}$} & NA & 76.92 & 61.54 & & & \\
\hline & \multicolumn{3}{|c|}{ Estimated Equation } & \multicolumn{3}{|c|}{ Constant Probability } \\
\hline & Dep $=0$ & Dep $=1$ & Total & Dep $=0$ & Dep $=1$ & Total \\
\hline $\mathrm{E}(\#$ of Dep $=0)$ & 10.13 & 2.87 & 13.00 & 6.50 & 6.50 & 13.00 \\
\hline $\mathrm{E}(\#$ of Dep $=1)$ & 2.87 & 10.13 & 13.00 & 6.50 & 6.50 & 13.00 \\
\hline Total & 13.00 & 13.00 & 26.00 & 13.00 & 13.00 & 26.00 \\
\hline Correct & 10.13 & 10.13 & 20.27 & 6.50 & 6.50 & 13.00 \\
\hline$\%$ Correct & 77.96 & 77.96 & 77.96 & 50.00 & 50.00 & 50.00 \\
\hline$\%$ Incorrect & 22.04 & 22.04 & 22.04 & 50.00 & 50.00 & 50.00 \\
\hline Total Gain* & 27.96 & 27.96 & 27.96 & & & \\
\hline Percent Gain ${ }^{* *}$ & 55.92 & 55.92 & 55.92 & & & \\
\hline
\end{tabular}

Beklenen tahmin tablo sonuçlarına göre, " 0 " değerine atanan 13 gözlemden 11 tanesi, “1” değerine atana 13 gözlemden 10'ü doğru tahmin 
edilmiştir. Kurulan 1. Lojistik Regresyon modelinin doğru tahminleme yüzdesi \%80,77'dir.

Tablo 7. Lojistik Regresyon 2. Model Çıktısı

\begin{tabular}{lllll}
\hline Variable & Coefficient & Std. Error & z-Statistic & Prob. \\
\hline Alacak Devir Hızı & 0.003926 & 0.001001 & 3.921162 & 0.0001 \\
Dönen Varlık Devir Hızı & 0.188519 & 0.236348 & 0.797635 & 0.4251 \\
Faiz Karşllama Oranı & -0.156925 & 0.088145 & -1.780303 & 0.0750 \\
Net Kar Marj1 & 11.58778 & 8.306558 & 1.395016 & 0.1630 \\
Sabit & -1.891483 & 0.842354 & -2.245473 & 0.0247 \\
McFadden R-squared & 0.435178 & Mean dependent var & 0.500000 \\
S.D. dependent var & 0.509902 & S.E. of regression & 0.401348 \\
Akaike info criterion & 1.167624 & Sum squared resid & 3.382683 \\
Schwarz criterion & 1.409566 & Log likelihood & -10.17912 \\
Hannan-Quinn criter. & 1.237295 & Deviance & 20.35824 \\
Restr. deviance & 36.04365 & Restr. log likelihood & -18.02183 \\
LR statistic & 15.68542 & Avg. log likelihood & -0.391505 \\
Prob(LR statistic) & 0.003472 & & \\
Obs with Dep=0 & 13 & Total obs & 26 \\
Obs with Dep=1 & 13 & & \\
\hline
\end{tabular}

Yukarıdaki Tabloda Lojistik Regresyon 2. Model Test sonucu mevcuttur. Model istatistiksel olarak anlamlıdır (Prob LR Statistic: 0. 003472) dolayısıyla çıktılar yorumlanabilir.

Lojistik Regresyon 1. Model Test sonucuna göre "Alacak Devir Hızı" değişkeni finansal olarak başarılı/başarısız firmaları belirleme hususunda istatistiksel olarak anlamlıdır. Alacak Devir Hızı, dönen varlık devir hızı, faiz karşılama oranı ve net kar marjı değişkenlerinin modele dahil edilmesiyle ulaşılan sonuçlara göre; Alacak Devir Hızı; firma başarımlarını belirleme hususunda ayırt edici rasyo olduğu tespit edilmiştir. Dönen varlık devir hızı, faiz karşılama oranı ve net kar marjının ise finansal anlamda başarılı/başarısız firmaları ayırt etmek için istatistiksel olarak anlamlı finansal oranlar olmadığı sonucuna ulaşılmıştır. 
Finansal Açıdan Başarısız Firmaların Lojistik Regresyon Analizi ile Tahmin Edilmesi: BİST 100 'de Bir Uygulama

Tablo 8. Lojistik Regresyon 2. Model Çıktılarının Yorumlanması

\begin{tabular}{|c|c|c|c|}
\hline Bağımsız Değişkenler & Test & Anlamlılık & Karar \\
\hline \multirow{4}{*}{ Alacak Devir Hızı } & \multirow{4}{*}{$\begin{array}{l}\text { Lojistik } \\
\text { Regresyon }\end{array}$} & \multirow{4}{*}{ 0. $0001<0,05$} & Alacak Devir Hızı \\
\hline & & & Başarılı/Başarısız \\
\hline & & & belirlenmesinde anlaml 1 bir \\
\hline & & & farklılık göstermektedir. \\
\hline \multirow{4}{*}{ Dönen Varlık Devir Hızı } & \multirow{4}{*}{$\begin{array}{l}\text { Lojistik } \\
\text { Regresyon }\end{array}$} & \multirow{4}{*}{$0.4251>0,05$} & $\begin{array}{llll}\text { Dönen } & \text { Varlık } & \text { Devir } & \text { Hızı }\end{array}$ \\
\hline & & & Başarılı/Başarısız \\
\hline & & & belirlenmesinde anlamlı bir \\
\hline & & & farklılık göstermemektedir. \\
\hline \multirow{4}{*}{ Faiz Karşılama Oranı } & \multirow{4}{*}{$\begin{array}{l}\text { Lojistik } \\
\text { Regresyon }\end{array}$} & \multirow{4}{*}{$0.0750>0,05$} & Faiz Karşılama \\
\hline & & & Başarılı/Başarısız \\
\hline & & & belirlenmesinde anlamlı bir \\
\hline & & & farklılık göstermemektedir. \\
\hline \multirow{3}{*}{ Net Kar Marji } & & \multirow{3}{*}{$0.1630>0,05$} & Net Kar Marjı Başarılı/Başarısız \\
\hline & Rogris & & firmaların belirlenmesinde anlamlı \\
\hline & & & bir farklılık göstermemektedir. \\
\hline
\end{tabular}

Tablo 9. Lojistik Regresyon 2. Modelinin Uygunluk Testi

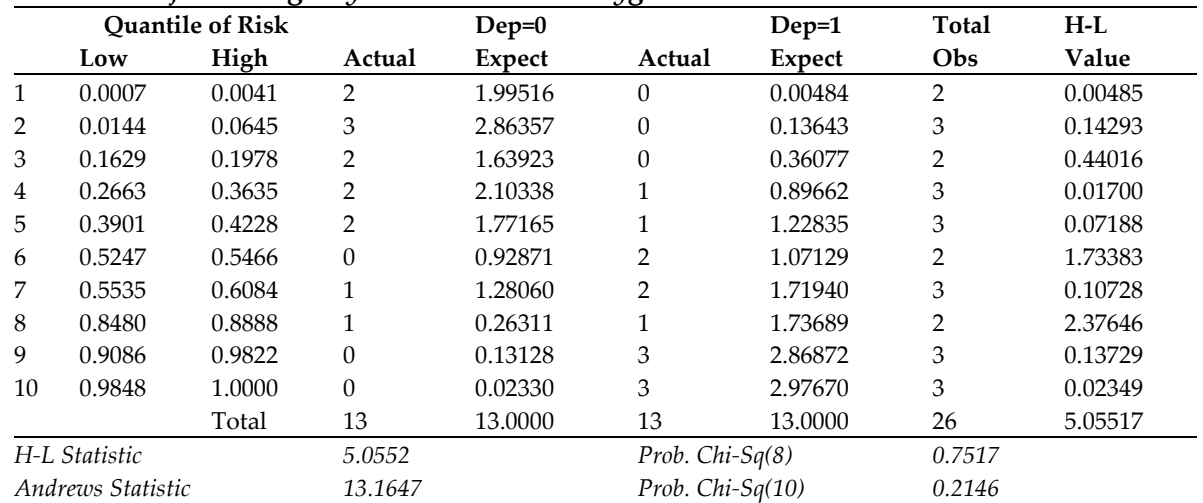

Tablo-8'de Lojistik Regresyon 2. Modelinin Uygunluk test sonucu tablosu yer almaktadır. Analiz sonucuna göre; Hosmer Lemeshow Prob. Chi-Sq(8) değeri $(0,7517) ; 00,01 / 0,05 / 0,10$ değerlerinden büyüktür bu nedenle 2. modelin uygun olduğuna karar verilir. 
Tablo 10. Lojistik Regresyon 2. Modelin Beklenen Tahmin Tablosu

\begin{tabular}{|c|c|c|c|c|c|c|}
\hline & \multicolumn{3}{|c|}{ Estimated Equation } & \multicolumn{3}{|c|}{ Constant Probability } \\
\hline & Dep $=0$ & Dep $=1$ & Total & Dep $=0$ & Dep $=1$ & Total \\
\hline $\mathrm{P}(\mathrm{Dep}=1)<=\mathrm{C}$ & 11 & 2 & 13 & 13 & 13 & 26 \\
\hline $\mathrm{P}(\mathrm{Dep}=1)>\mathrm{C}$ & 2 & 11 & 13 & 0 & 0 & 0 \\
\hline Total & 13 & 13 & 26 & 13 & 13 & 26 \\
\hline Correct & 11 & 11 & 22 & 13 & 0 & 13 \\
\hline$\%$ Correct & 84.62 & 84.62 & 84.62 & 100.00 & 0.00 & 50.00 \\
\hline$\%$ Incorrect & 15.38 & 15.38 & 15.38 & 0.00 & 100.00 & 50.00 \\
\hline Total Gain* & -15.38 & 84.62 & 34.62 & & & \\
\hline \multirow[t]{3}{*}{ Percent Gain** } & NA & 84.62 & 69.23 & & & \\
\hline & \multicolumn{3}{|c|}{ Estimated Equation } & \multicolumn{3}{|c|}{ Constant Probability } \\
\hline & Dep $=0$ & Dep $=1$ & Total & Dep $=0$ & Dep $=1$ & Total \\
\hline $\mathrm{E}(\#$ of Dep $=0)$ & 9.62 & 3.38 & 13.00 & 6.50 & 6.50 & 13.00 \\
\hline $\mathrm{E}(\#$ of Dep $=1)$ & 3.38 & 9.62 & 13.00 & 6.50 & 6.50 & 13.00 \\
\hline Total & 13.00 & 13.00 & 26.00 & 13.00 & 13.00 & 26.00 \\
\hline Correct & 9.62 & 9.62 & 19.24 & 6.50 & 6.50 & 13.00 \\
\hline$\%$ Correct & 74.00 & 74.00 & 74.00 & 50.00 & 50.00 & 50.00 \\
\hline$\%$ Incorrect & 26.00 & 26.00 & 26.00 & 50.00 & 50.00 & 50.00 \\
\hline Total Gain* & 24.00 & 24.00 & 24.00 & & & \\
\hline Percent Gain ${ }^{* *}$ & 48.00 & 48.00 & 48.00 & & & \\
\hline
\end{tabular}

Beklenen tahmin tablo sonucuna göre, "0" değerine atanmış 13 gözlemden 11 adedi, " 1 ” değerine atana 13 gözlemden 11 'i doğru tahmin edilmiştir. Kurulan 2. Lojistik Regresyon modelinin doğru tahminleme yüzdesi \%84.62 olmuştur. 2. Logit Modelin doğru tahminleme yüzdesinin; 1. Logit Modelin doğru tahminleme yüzdesi olan $\% 80,77^{\prime}$ den daha yüksek olduğu tespit edilmiştir.

Tablo 11. Lojistik Regresyon 3. Model Çıktısı

\begin{tabular}{lllll}
\hline Variable & Coefficient & Std. Error & z-Statistic & Prob. \\
\hline Özkaynak Devir Hızı & 2.034527 & 1.489193 & 1.366194 & 0.1719 \\
Aktif Devir Hızı & -2.583421 & 2.839966 & -0.909666 & 0.3630 \\
Alacak Devir Hızı & 0.013065 & 0.009876 & 1.322879 & 0.1859 \\
Cari Oran & 0.977388 & 1.077654 & 0.906959 & 0.3644 \\
Borç/Özkaynak & -0.915461 & 0.725449 & -1.261923 & 0.2070 \\
Dönen Varlık Devir Hızı & 1.314719 & 1.327957 & 0.990032 & 0.3222 \\
Duran Varlı/Özkaynak & -1.650813 & 1.269299 & -1.300571 & 0.1934 \\
Faaliyet Kar Marjı & 22.17488 & 10.21233 & 2.171382 & 0.0299 \\
Faiz Karşılama Oranı & -0.074418 & 0.036125 & -2.060018 & 0.0394 \\
Maddi Duran Varlık Devir Hızı & -0.510530 & 0.368002 & -1.387304 & 0.1653 \\
Ticari Borç Devir Hızı & -0.582454 & 0.408753 & -1.424953 & 0.1542 \\
Sabit & -4.847679 & 3.231903 & -1.499946 & 0.1336 \\
McFadden R-squared & 0.728112 & Mean dependent var & 0.500000 \\
S.D. dependent var & 0.509902 & S.E. of regression & 0.332757 \\
Akaike info criterion & 1.299994 & Sum squared resid & 1.550185 \\
Schwarz criterion & 1.880653 & Log likelihood & -4.899916 \\
Hannan-Quinn criter. & 1.467203 & Deviance & 9.799832 \\
Restr. deviance & 36.04365 & Restr. log likelihood & -18.02183
\end{tabular}




\begin{tabular}{llll} 
LR statistic & 26.24382 & Avg. log likelihood & -0.188458 \\
Prob(LR statistic) & 0.005969 & & \\
Obs with Dep $=0$ & 13 & Total obs & 26 \\
Obs with Dep $=1$ & 13 & & \\
\hline
\end{tabular}

Yukarıdaki yer alan Tablo 10' da Lojistik Regresyon 3. Model Test sonucu mevcuttur. Model istatistiksel olarak anlamlıdır (Prob LR Statistic: 0. 005969) dolayısıyla çıtılar yorumlanabilir.

Oluşturulan 3. modelde tüm değişkenler aynı anda analize dahil edilmiştir. Lojistik Regresyon 3. Model Test sonucuna göre "Faaliyet Kar Marjı" ve "Faiz Karşılama Oranı" değişkenleri finansal olarak başarılı veya başarısız firmaları belirlemede istatistiksel olarak anlamlıdır. Faaliyet kar marjı ve faiz karşılama oranı rasyolarının firma başarımlarını belirlemede ayırt edici rasyolar olduğu tespit edilmiştir. Ancak modele aynı anda dahil edilen; özkaynak devir hızı, aktif devir hızı, alacak devir hızı, cari oran, borç/özkaynak, dönen varlık devir hızı, duran varlık/özkaynak, faaliyet kar marjı, maddi duran varlık devir hızı ve ticari borç devir hızı finansal oranlarının ise finansal olarak başarılı veya başarısız firmaları ayırt etmede istatistiksel olarak anlamlı olmadığ sonucuna ulaşılmıştır.

\section{Tablo 12. Lojistik Regresyon 3. Modelin Uygunluk Testi}

\begin{tabular}{|c|c|c|c|c|c|c|c|c|}
\hline & \multicolumn{3}{|c|}{ Quantile of Risk } & \multicolumn{2}{|l|}{ Dep $=0$} & \multirow{2}{*}{$\begin{array}{l}\text { Dep=1 } \\
\text { Expect }\end{array}$} & \multirow{2}{*}{$\begin{array}{l}\text { Total } \\
\text { Obs }\end{array}$} & \multirow{2}{*}{$\begin{array}{l}\text { H-L } \\
\text { Value }\end{array}$} \\
\hline & Low & High & Actual & Expect & Actual & & & \\
\hline 1 & 9.E-05 & 0.0023 & 2 & 1.99764 & 0 & 0.00236 & 2 & 0.00236 \\
\hline 2 & 0.0026 & 0.0135 & 3 & 2.97587 & 0 & 0.02413 & 3 & 0.02432 \\
\hline 3 & 0.0148 & 0.0528 & 2 & 1.93234 & 0 & 0.06766 & 2 & 0.07002 \\
\hline 4 & 0.0618 & 0.1243 & 2 & 2.69876 & 1 & 0.30124 & 3 & 1.80172 \\
\hline 5 & 0.1627 & 0.2147 & 3 & 2.43959 & 0 & 0.56041 & 3 & 0.68915 \\
\hline 6 & 0.6118 & 0.6822 & 1 & 0.70598 & 1 & 1.29402 & 2 & 0.18926 \\
\hline 7 & 0.8005 & 0.9900 & 0 & 0.23591 & 3 & 2.76409 & 3 & 0.25604 \\
\hline 8 & 0.9932 & 0.9943 & 0 & 0.01258 & 2 & 1.98742 & 2 & 0.01266 \\
\hline 9 & 0.9988 & 1.0000 & 0 & 0.00127 & 3 & 2.99873 & 3 & 0.00127 \\
\hline \multirow[t]{2}{*}{10} & 1.0000 & 1.0000 & 0 & 6.4E-05 & 3 & 2.99994 & 3 & $6.4 \mathrm{E}-05$ \\
\hline & & Total & 13 & 13.0000 & 13 & 13.0000 & 26 & 3.04687 \\
\hline \multicolumn{3}{|c|}{$\overline{H-L}$ Statistic } & \multicolumn{2}{|l|}{3.0469} & \multicolumn{2}{|c|}{ Prob. Chi-Sq(8) } & \multirow{2}{*}{\multicolumn{2}{|c|}{$\begin{array}{l}0.9314 \\
0.0074\end{array}$}} \\
\hline \multicolumn{3}{|c|}{ Andrews Statistic } & \multicolumn{2}{|l|}{24.0590} & \multicolumn{2}{|c|}{ Prob. Chi-Sq(10) } & & \\
\hline
\end{tabular}

Tablo-11'de Lojistik Regresyon 3. Modelinin Uygunluk test sonuç tablosu yer almaktadır. Elde edilen analiz sonucuna göre; Hosmer Lemeshow Prob. Chi-Sq (8) değeri (0, 9314); 00,01/0,050/0,10 
değerlerinden büyüktür bu nedenle 3. modelin uygun olduğuna karar verilir.

Ayrıca Andrews Statistic sonucunda elde edilen Prob. Chi-Sq (8) değeri (0.0074); 0,01/0,05/0,10 değerlerinden küçük olduğu için de modelin istatistiksel olarak uygunluğuna karar verilir.

Tablo 13. Lojistik Regresyon 3. Model Çıktılarının Yorumlanması

\begin{tabular}{|c|c|c|c|}
\hline Bağımsız Değişkenler & Test & Anlamlılık & Karar \\
\hline Aktif Devir Hızı & $\begin{array}{l}\text { Lojistik Regresyon } \\
\text { Analizi }\end{array}$ & $0.3630>0,05$ & $\begin{array}{l}\text { Aktif Devir Hızı } \\
\text { Başarılı/Başarısız } \\
\text { firmaların } \\
\text { belirlenmesinde anlamlı } \\
\text { bir farklılık } \\
\text { göstermemektedir. } \\
\text { Özkavnak }\end{array}$ \\
\hline Özkaynak Devir Hızı & $\begin{array}{l}\text { Lojistik Regresyon } \\
\text { Analizi }\end{array}$ & $0.1719>0,05$ & $\begin{array}{l}\text { Başarılı/Başarısız } \\
\text { firmaların } \\
\text { belirlenmesinde anlamlı } \\
\text { bir farklılık } \\
\text { göstermemektedir. } \\
\text { Alacak Devir Hızı }\end{array}$ \\
\hline Alacak Devir Hızı & $\begin{array}{l}\text { Lojistik Regresyon } \\
\text { Analizi }\end{array}$ & $0.1859>0,05$ & $\begin{array}{l}\text { Başarılı/Başarısız } \\
\text { firmaların } \\
\text { belirlenmesinde anlamlı } \\
\text { bir farklılık } \\
\text { göstermemektedir. }\end{array}$ \\
\hline $\begin{array}{l}\text { Toplam } \\
\text { Borç/Özkaynaklar }\end{array}$ & $\begin{array}{l}\text { Lojistik Regresyon } \\
\text { Analizi }\end{array}$ & $0.2070>0,05$ & $\begin{array}{l}\text { Toplam } \\
\text { Borç/Özkaynaklar } \\
\text { Başarılı/Başarısız } \\
\text { firmaların } \\
\text { belirlenmesinde anlamlı } \\
\text { bir farklılık } \\
\text { göstermemektedir. }\end{array}$ \\
\hline Cari Oran & $\begin{array}{l}\text { Lojistik Regresyon } \\
\text { Analizi }\end{array}$ & $0.3644>0,05$ & $\begin{array}{l}\text { Cari Oran } \\
\text { Başarılı/Başarısız } \\
\text { firmaların } \\
\text { belirlenmesinde anlamlı } \\
\text { bir farklılık } \\
\text { göstermemektedir. }\end{array}$ \\
\hline Dönen Varlık Devir Hızı & $\begin{array}{l}\text { Lojistik Regresyon } \\
\text { Analizi }\end{array}$ & $0.3222>0,05$ & $\begin{array}{l}\text { Dönen Varlık Devir Hızı } \\
\text { Başarılı/Başarısız } \\
\text { firmaların } \\
\text { belirlenmesinde anlamlı } \\
\text { bir farklılık } \\
\text { göstermemektedir. }\end{array}$ \\
\hline $\begin{array}{l}\text { Duran Varlık/Öz } \\
\text { Kaynak }\end{array}$ & $\begin{array}{l}\text { Lojistik Regresyon } \\
\text { Analizi }\end{array}$ & $0.1934>0,05$ & $\begin{array}{l}\text { Başarılı/Başarısız } \\
\text { firmaların } \\
\text { belirlenmesinde anlamlı }\end{array}$ \\
\hline
\end{tabular}


Finansal Açıdan Başarısız Firmaların Lojistik Regresyon Analizi ile Tahmin Edilmesi: BİST 100 'de Bir Uygulama

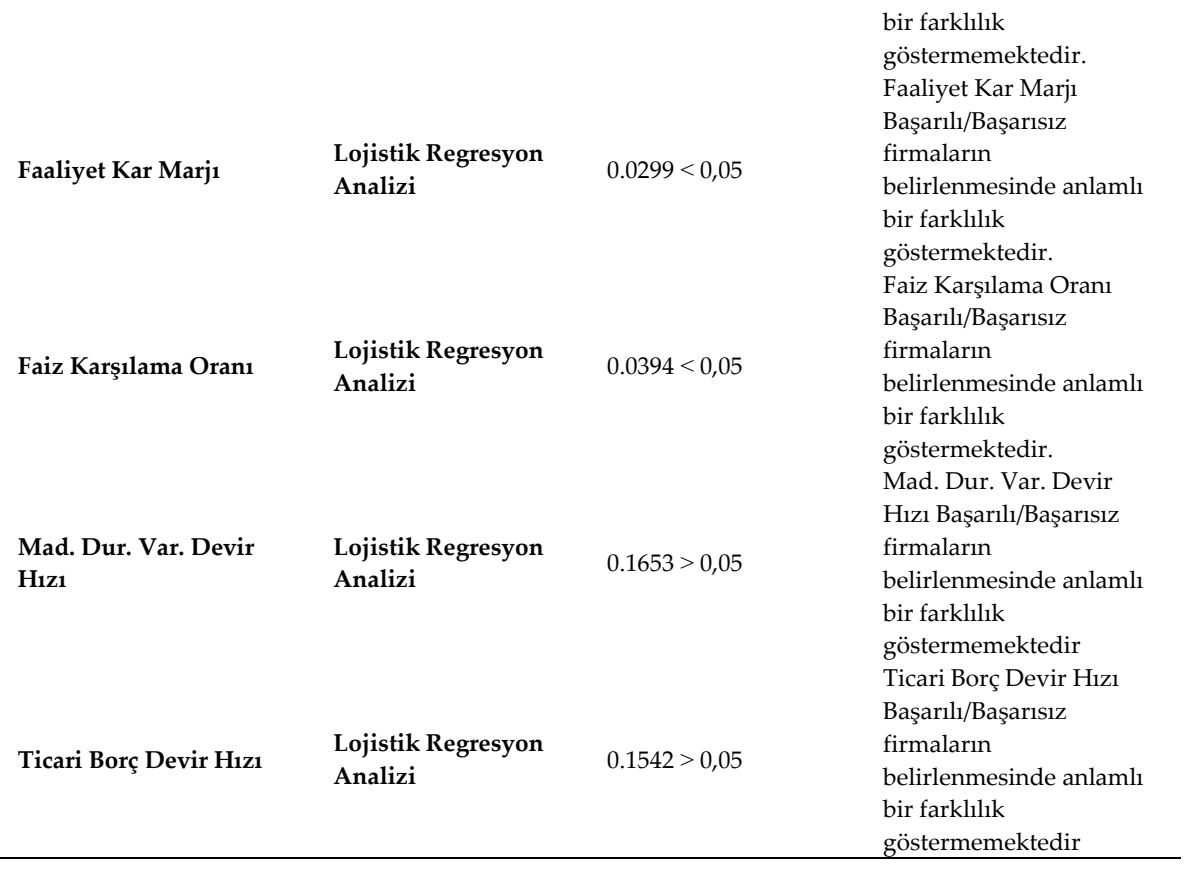

Tablo 14. Lojistik Regresyon 3. Modelin Beklenen Tahmin Tablosu

\begin{tabular}{|c|c|c|c|c|c|c|}
\hline & \multicolumn{3}{|c|}{ Estimated Equation } & \multicolumn{3}{|c|}{ Constant Probability } \\
\hline & Dep $=0$ & Dep $=1$ & Total & Dep $=0$ & Dep $=1$ & Total \\
\hline $\mathrm{P}(\mathrm{Dep}=1)<=\mathrm{C}$ & 12 & 1 & 13 & 13 & 13 & 26 \\
\hline$P($ Dep $=1)>C$ & 1 & 12 & 13 & 0 & 0 & 0 \\
\hline Total & 13 & 13 & 26 & 13 & 13 & 26 \\
\hline Correct & 12 & 12 & 24 & 13 & 0 & 13 \\
\hline$\%$ Correct & 92.31 & 92.31 & 92.31 & 100.00 & 0.00 & 50.00 \\
\hline$\%$ Incorrect & 7.69 & 7.69 & 7.69 & 0.00 & 100.00 & 50.00 \\
\hline Total Gain* & -7.69 & 92.31 & 42.31 & & & \\
\hline \multirow[t]{3}{*}{ Percent Gain** } & NA & 92.31 & 84.62 & & & \\
\hline & \multicolumn{3}{|c|}{ Estimated Equation } & \multicolumn{3}{|c|}{ Constant Probability } \\
\hline & Dep $=0$ & Dep $=1$ & Total & Dep $=0$ & Dep $=1$ & Total \\
\hline $\mathrm{E}(\#$ of $\mathrm{Dep}=0)$ & 11.49 & 1.51 & 13.00 & 6.50 & 6.50 & 13.00 \\
\hline $\mathrm{E}(\#$ of $\mathrm{Dep}=1)$ & 1.51 & 11.49 & 13.00 & 6.50 & 6.50 & 13.00 \\
\hline Total & 13.00 & 13.00 & 26.00 & 13.00 & 13.00 & 26.00 \\
\hline Correct & 11.49 & 11.49 & 22.97 & 6.50 & 6.50 & 13.00 \\
\hline$\%$ Correct & 88.36 & 88.36 & 88.36 & 50.00 & 50.00 & 50.00 \\
\hline$\%$ Incorrect & 11.64 & 11.64 & 11.64 & 50.00 & 50.00 & 50.00 \\
\hline Total Gain* & 38.36 & 38.36 & 38.36 & & & \\
\hline Percent Gain ${ }^{* *}$ & 76.71 & 76.71 & 76.71 & & & \\
\hline
\end{tabular}

Beklenen tahmin tablosu sonuçlarına göre, 0 değerine atanan 13 gözlemden 12 tanesi, 1 değerine atana 13 gözlemden 12 'si doğru tahmin 
edilmiştir. 3. Logit model, tüm değişkenlerin hepsinin bir arada modele dahil edilmesi ile kurulmuştur. Netice olarak en doğru tahminleme yüzdesine sahip model \%92.31 ile 3. model olduğu görülmektedir.

\section{Tartışma ve Sonuç}

BİST 100 Endeksinde yer alan 26 firma için; başarılı ve başarısız firmaların belirlenmesinde hangi finansal rasyoların açıklayıcı, tespit edici ve belirleyici olabileceğini araştırmak için Lojistik Regresyon analizi yapılmıştır.

Bunun için 3 ayrı Lojistik Regresyon modeli kurulmuş olup, 3. modelde tüm değişkenler aynı anda modele dahil edilmiştir. Kurulmuş olan farklı modeler ile finansal başarısızlığın tahmin edilmeye çalışılması; çalışmayı yapılan diğer çalışmalardan farklılaştırmaktadır. Kurulan tüm modeller istatistiksel olarak anlamlı olup 3. modelin ise doğru tahminleme yüzdesi diğerlerinden daha yüksek olduğu tespit edilmiştir. Kurulan 3. Logit Model sonuçlarına göre; başarılı ve başarısız firmaların belirlenmesinde "faiz karşılama oranı" ve "faaliyet kar marjı" rasyolarının istatistiksel olarak anlamlı belirleyici rasyolar olabileceği sonucuna ulaşılmıştır. Ancak araştırma sonucuna göre; modele dâhil edilen alacak finansal rasyolardan; alacak devir hızı, cari oran, aktif devir hızı, özkaynak devir hızı, alacak devir hızı, toplam borç/özkaynaklar, cari oran, dönen varlık devir hızı, duran varlık/öz kaynak, faaliyet kar marjı, maddi duran varlık devir hızı, ticari borç devir hızı rasyolarının başarılı ve başarısız firmaların belirlemesinde istatistiksel olarak anlamlı ve belirleyici rasyolar olmadığı sonucuna ulaşılmıştır.

Çalışmada yer alan modelin firma sahipleri ve firmaya yatırım yapmayı düşünenlerin, firma faaliyetlerinin ne derecede başarılı ya da başarısız yönettikleri konusunda bir öngörü ve denetim aracı olarak da kullanılabilecektir. Çalışma bu yönü ile literatüre katkı sunmaktadır . İlgili modelin finansal rasyolar ile birlikte firmaların başarısızlığına neden olabilecek çeşitli makroekonomik verileride ele alacak bir çalışmanın ortaya koyulması, kullanıcılar açısından daha geniş kapsamlı bir bakış ortaya koyabilecektir. 


\title{
EXTENDED ABSTRACT
}

\section{Estimating Financially Failed Firms Using Logistic Regression Analysis: An Application in BIST 100}

\author{
Merve Arslan- İsmail Erkan Çelik \\ Haliç University-Doğuş University
}

Financial failure can be defined as the difficulty or inability of the firm to fulfill its obligations. In fact, the financial failure situation is the decrease in the solvency of the companies or the disappearance of them completely. In order for any firm to qualify as financially unsuccessful, it must meet certain criteria. When the literature on the subject is examined in determining the financial failure many different criteria have been encountered such as the inability of companies to pay their due obligations, writing bad checks, failing to pay bond interest, having made a loss for three consecutive years, losing $10 \%$ of their asset amount, decreasing their equity, stopping the production wheel or going bankrupt.

Businesses are established with the priority of profit, and their life at the technical level is thought to last forever. However, businesses may encounter different problems in this process. Failure to detect and solve these problems causes failures of businesses. Failure is a situation that businesses do not want to face. While some of the businesses may fail at the beginning of their life processes after 1.2 years in the establishment phase, some other businesses can develop and continue their growth processes successfully. These are economic failures and financial failures. In general terms the concept of financial failure; It is possible to define it as experiencing deterioration in the financial structure, getting into trouble, not being able to pay the debts, failure due to the continuation of the troubled process, and finally the realization of bankruptcy. Bankruptcy is a process that starts with financial problems and ends in court and is a special case of financial failure.

Financial failure is one of the most important problems that companies may face. Especially in terms of our country, which has a fragile economic structure, it is necessary to predict the financial ratios that cause financial failure in companies and to take the necessary measures to prevent failure. 
Financial failure may arise from a variety of internal/external reasons, but it is clear that managers cannot interfere with external factors. On the other hand, it is possible to predict and intervene in the causes of failure within the company. For this reason, recent studies have focused on which rates cause financial failures and which rates are determinant in determining financial failure. In the detection of financial failure; The use of estimation methods such as artificial neural networks, logistic regression analysis, discriminant analysis has been encountered. The aim of this study is to create a meaningful and reliable model in measuring the financial failures of companies whose shares are traded on BIST100. With this aim, firstly, "financial failure" was researched and it was tried to distinguish which companies could be financially successful and unsuccessful. Afterwards, financial ratios were calculated and logistic regression analysis was made with these financial ratios.

In the conditions of increasing competition in the world, it is only possible for businesses to reach their goals if they are financially strong. Firms should either anticipate and minimize the risks that cause financial failure or, if possible, eliminate them completely. Anticipating financial failures; It is a very important issue for businesses to determine the financial risks that may arise in the future and to take precautions in advance. The main purpose of this study is to examine the companies listed in the Borsa Istanbul 100 Index (BIST 100); It is the development of various logistic regression models in order to reveal which ratios are statistically significant or not in identifying and categorizing financially successful and unsuccessful companies, which can be an indicator of financial failure, and to predict failure with the help of these determined ratios. For this purpose, the financial ratio data of 26 companies in BIST 100 for 2019 were used in the study.

İn this study 3 different Logistic Regression models were established and in the 3rd model, all variables were included in the model at the same time. Trying to predict financial failure with different models that have been established; differentiates this study from other studies. All the established models were statistically significant, and the correct estimation percentage of the 3rd model was found to be higher than the others. According to the results of the 3rd Logit Model established; It has been concluded that "interest coverage ratio" and "operating profit 
margin" ratios can be statistically significant determinants in determining successful and unsuccessful companies. According to the results of the research, statistically insignificant and non-deterministic rates in determining successful and unsuccessful companies; receivables turnover, current ratio, asset turnover, equity turnover, receivables turnover, total debt/equity, current ratio, current asset turnover, fixed asset/equity, operating profit margin, tangible asset turnover, trade debt turnover ratios.

The model in the study can also be used as a foresight and control tool on how successful or unsuccessful the company's activities are managed by the company owners and those who are considering investing in the company. The study contributes to the literature with this aspect. The presentation of a study that will deal with the financial ratios of the relevant model, as well as various macroeconomic data that may cause the failure of the companies, will provide a more comprehensive view from the users' point of view.

\section{Kaynakça / References}

Aktaş, R. (1997). Mali başarısızlık (İşletme Riski) tahmin modelleri. Ankara: Türkiye Iş Bankası Kültür Yayınları.

Aktaş, R., Doğanay, M. ve Yildiz B. (2003). Finansal başarısızlığın öngörülmesi: İstatistiksel yöntemler ve yapay sinir ağı karşılaştırması. Ankara Üniversitesi SBF Dergisi, 58(4), 1-24.

Altman, E.I. (1968). Financial ratios, discriminant analysis and prediction of corporate failure. Journal of Finance, 23(4), 589-609.

Altaş D. ve Giray, S. (2005). Mali başarısızlığın çok değişkenli istatistiksel yöntemlerle belirlenmesi: Tekstil sektörü örneği. Marmara Üniversitesi Sosyal Bilimler Dergisi, 5, 13-28.

Beaver, W.H. (1968). Market prices, financial ratios and the prediction of failure. Journal of Accounting Research, 6(2), 179-192.

Beaver, W.H. (1966). Financial ratios as predictors of failure, empirical research in accounting: Selected studies. Journal of Accounting Research, 5, 71-111.

Büker, S. Sevil, G. ve Aşıkoğlu, R. (2007). Finansal yönetim. Ankara: Özkan Matbaacilık.

Doğrul, Ü. (2009). Finansal başarısızlık ve finanasal başarısızlık tahmini: Hisse senetleri IMKB'de işlem gören sinai işletmeler üzerinde bir uygulama. 
(Yayımlanmış yüksek lisans tezi). Mersin Üniversitesi Sosyal Bilimler Enstitüsü, Mersin.

Gitman, L. J. (1992). Basic managerial finance. NewYork: Harper Collins Publishers.

Kap (2021). wwww.kap.org.tr. Erişim: 25.05.2021.

Mertler, C.A. ve Vannatta, R. A. (2005). Advanced and multivariate statistical methods: Practical application and interpretation. Glendale: Pyrczak Publishing.

Ohlson, J.A. (1980). Financial ratios and the probabilistic prediction of bankruptcy. Journal of Accounting Research, 18(1), 109-131.

Siedlecki, R. (2014). Forecasting company financial distress using the gradient measurement of development and s-curve. Procedia Economics and Finance, 12, 597-606.

Tamari, M. (1966). Financial ratios as a means of forecasting bankruptcy. Management International Review, 23(4), 15-21.

Weitzel, W. ve Jonsson, E. (1989). Dicline in organizations: A literature integration and extension. Administarative Science Quarterly, 34(1), 91109.

Zmijewski, M.E. (1984) Methodological issues related to the estimation of financial distress prediction models. Journal of Accounting Research, 22, 59-82.

\section{Kaynakça Bilgisi / Citation Information}

Arslan, M. ve Çelik, İ. E. (2021). Finansal açıdan başarısız firmaların lojistik regresyon analizi ile tahmin edilmesi: BİST 100'de bir uygulama. OPUS-Uluslararası Toplum Araştırmaları Dergisi, 18(42), 5631-5650. DOI: 10.26466/opus.950625. 